\title{
Resilient Cosmologies: Water Deities and Divine Agency in Post-Mao China
}

Koen Wellens

(University of Oslo)

\begin{abstract}
This article explores ritual practices among the Premi people in Southwest China at the beginning of the new millennium. Living in the periphery of Tibetan, Han Chinese and other Tibeto-Burman ethnic groups, Premi villagers have continued to keep an understanding of how the world works that is markedly different from their neighbours. The all-encompassing economic development of China is posing new challenges to the intangible entities in Premi cosmology. In its management of forests, waterways or birth control, the Chinese state is increasingly interfering with Premi ways of dealing with their surroundings. The chapter proposes to focus on the way one category of intangible entities of Premi cosmology, the lwéjabu or water deities, are seen as acting towards these challenges, rather than on the underlying ontological changes. An event where a member of a neighbouring ethnic group becomes an unwitting participant in a Premi medium séance, makes the case for approaching extra-human forms of agency by beginning with the 'work' or 'effect' of the divine entities.
\end{abstract}

Keywords: China ; Yunnan ; Sichuan ; Premi ; Nuosu ; Nature ; Cosmology; Deities ; Agency

This chapter is concerned with the changing relationship between ritual practice and cosmological beliefs of the Premi people. ${ }^{1}$ The question is raised of how such practice responds to challenges to local beliefs, either those of the passed encroachment of Maoism or those of the increasing contacts with Chinese modernity. In order for ritual practices to be seen as relevant, local villagers cannot frame such challenges in terms of multiculturalist ontologies of Western social science, where one nature is viewed as having generated different cultures. Recent anthropological discussions of the 
relationship between humans and non-humans have criticised the quintessential dichotomy between nature and culture (Descola 2013). From Amazonian anthropology, the conception of perspectivism challenges the opposition between relativism and universalism and provides an appealing new way of conceptualising universality as the product of forms of agency attributed to nonhuman beings (Viveiros de Castro 1998, 470). When Premi people in Southwest China are once more conducting and participating in rituals for the $l w e ́ j a b u^{2}$ or water deities after a break of almost a generation during the Maoist period, are they merely doing so because they feel compelled to keep order and balance in their shared cosmological beliefs? Do rituals that ostensibly are similar to those that can be found in Chinese ethnographies of the 1950s mean today what they did then? Are they referring to the same beliefs and understanding of the cosmos, and if so, to what extent is cosmology shared by different actors? The post Mao retraction of the party-state from the remote mountains of the Southwest engendered both an ideological relaxation and the demise of communist social security, triggering a revival of ritual practice. When the partystate once more penetrates the lives and livelihoods of the villagers through policies of birth control, forest protection or economic policies it does not seek yet again to replace Premi cosmology with a specific political ideology. This time, Premi villagers and their ritual experts are left with the task of accommodating the ever more encompassing interferences in their daily lives and the way they see the world. The article will argue that villagers cope with these challenges by ascribing deities and other spiritual entities of traditional Premi cosmology with their own subjective agency. In following Diana Espírito Santo and Ruy Blanes, I propose to approach such entities not by looking at ontological definitions but by considering the effect deities and spirits have in Premi society (Espírito Santo and Blanes 2014). That implies to start at the other end and move the ethnographic gaze from tangible to invisible, from manifestation to agency, and, consequently, move into the social plane 'where extensions leave markings, traces, paths, and, ultimately, "evidence."” (Espírito Santo and Blanes 2014, 6).

\section{A Nuosu Visit to a Premi Medium}

Premi culture in villages of Muli County in Sichuan and Ninglang County in Yunnan has been remarkably resilient and in the new millennium it is clearly distinguishable 
through such markers as language, ritual practices and a strong-shared sense of common descent. At the same time, with around 60,000 people, the Premi constitute a numerically small ethnic group surrounded by and interspersed with different other groups with whom they have interacted over centuries. They also have a long history of migration over a large area of the Southwest. ${ }^{3}$ As a result, while constituting clearly bounded cultural communities, these communities can be rather culturally divergent from each other. In Sichuan and in the adjacent area of Northwest Yunnan, Premi communities have to a different extent been subjected to a forced integration into the realm of monastic Buddhism at the hands of their Tibetanised rulers. The onslaught on Premi traditional beliefs during the Mao period was definitely much more penetrating and all-encompassing, but, in the larger scheme of history, also much more short-lived than the Tibetan Buddhist impact. While the following period of more liberal policies — starting with Deng Xiaoping in the late 1970s - has enabled a restoration and even a revitalisation of traditional ritual practices, the forces of Chinese modernity are also increasingly challenging underlying cosmological beliefs. After the start of the new millennium, most Premi villages count a segment of youngsters who have had sustained contact with larger Chinese society, either through participation in the official school system or through having spent time as migrant workers in the developing cities of Southwest China. With the spread of satellite TV, cheap DVD's and, increasingly, Internet access through cell phones, Chinese mainstream culture has reached even the more remote villages of the Himalayan foothills. Furthermore, the modernisation of Premi ethnic identity as a minzu, or officially recognised ethnic group, in Chinese society and its potential resource in the commodification of 'exotic' culture in the ethnic tourist industry of Yunnan has imbued traditional ritual practices with new meaning and values. Nevertheless, local ways of understanding the universe and its workings have survived and the claims by Premi cosmology to universality do not unavoidably lose out to the challenges of increased interactions with other ethnic groups or the increasing contacts with wider Chinese society. Deities that are considered to be powerful, such as the lwéjabu now play an important role in assisting humans in addressing new challenges such as providing male offspring under strict government family planning policies or regulating the relationship with nature in the context of increasingly invasive state policies on forest protection. 
In a period where the claims to validity of local cosmologies are increasingly challenged how can the deities be seen as possessing agency? If we take as a starting point a 'pragmatics of effect' (Espírito Santo and Blanes 2014, 17) some clues in answering this question might be obtained from the following event I witnessed during fieldwork in a Premi village on the Yunnan-Sichuan border somewhere in the beginning of the new millennium.

On one of my visits to the soma or local medium ${ }^{4}$ in the village, I was accompanied by Old Trousers ${ }^{5}$, my research assistant who, in spite of what his name might suggest, was also the young and smart public security officer of the township. At the end of the interview, to my surprise, Old Trousers politely requested if he could consult the soma himself to find out what could be done to keep his relatives, living a few days walking from our field site, safe and sound. The soma, a vigorous grandfather approaching the age of seventy, was the only medium in the township. He was famed in the area for being the direct channel through which the lwéjabu communicated with the villagers. After having inquired about the details of the living surroundings of Old Trousers' relatives, the soma went into a trance-like state with his eyes closed and his legs trembling. After some time, in a markedly different voice, he declared: 'Keep the lake near the house free from pollution and all will be safe!' After the séance was over and we had left the house of the soma, Old Trousers clearly expressed that he intended to follow the advice given to him. Even to an anthropologist having spent several years in the area, this was a remarkable turn of events. First of all, Old Trousers was a police officer and a young and dedicated member of the declaredly atheist Chinese Communist Party. What made his actions and convictions even more surprising was the fact that he was a member of the Nuosu, an ethnic group that is culturally distinct from the Premi, the ethnic group to which the soma belonged. Not only are the two ethnic groups clearly distinguishable by different cultural markers such as language, dress or ritual practices, but also among many of their neighbours the Nuosu have a certain reputation of sticking to strict maintenance of ethnic boundaries. Even after fifty years of official policies of 'ethnic unity', intermarriages between Nuosu and Premi are still very rare outside the urban areas. In other words, Old Trousers had more than enough reasons for not taking seriously what an old man 
from a different ethnic group had to say about the protection of his relatives by water deities.

Premi and Nuosu traditional understanding of how the world is organised, their systems of classification, the nature of the spirits and deities and how they interact with humans might present a number of similarities to outside observers. On the other hand, these same observers will also be able to register many points where Premi and Nuosu hold that they see the world rather differently, and therefore act differently upon it, such as transpires in their ritual practice. While, for example, both Premi and Nuosu traditionally cremate the body of the deceased, several Premi people expressed their abhorrence to me over the fact that Nuosu do not pick out the pieces of bone from among the left over ashes after burning the corpse. How can the souls of the deceased find peace when their surviving descendants do not show more respect for their corporal remains? Nonetheless, Old Trousers seemed to transcend differences in cosmology by recognising the power of the lwéjabu in being able to protect his relatives, ascribing in this way a level of agency to the water deities transgressing ethnic boundaries. In a traditional way of setting up a dichotomy between nature and culture, positing a single nature up against multiple cultures, Old Trousers' convictions could be construed as merely being vested in accepting that the cosmos (nature) must necessarily be the same for Nuosu and Premi since they live in the same world. But then again, Old Trousers clearly acknowledged the competence of the soma in both communicating with the lwéjabu as well as interpreting the response by the water deities. He realised also it was not up to him to decide whether the lwéjabu had such powers or whether they at all existed. And this view was shared by the soma and the other villagers I talked to: although they could not remember ever having had a Nuosu - let alone a Nuosu police officer — coming to consult the soma, people understood his motives and did not question his logic.

In his work on Amerindian perspectivism, Eduardo Viveiros de Castro sets out to formulate alternative modes of addressing the classic Western 'multiculturalist' cosmologies with an implied unity of nature and a plurality of cultures (Viveiros de Castro 1998, 470). His concept of perspectivism is drawn from Amazonian cosmology where subjectivities easily change appearance between animals, human or spirits. ${ }^{6}$ This is significantly different from Tibeto-Burman ways of understanding of 
how different beings exist in the world. The application of Viveiros de Castro's concept of 'animism' might even obfuscate some aspects of Premi ontology where certain living or inert objects seem to be endowed with their own subjectivity but who are in fact only ontologically relevant because they are associated with certain deities and spirits. The killing of a deer, cutting of a tree or polluting of a river is not a transgression against these entities in themselves but against the deities who own, cherish or abide in them. Nevertheless, on the analytical level, Viveiros de Castro alerts us to alternative modes of conceptualising 'extra-human intentionalities' and points out that the space between nature and society is social itself (Viveiros de Castro 1998, 472-3, 2004, 467).

Why a member of the Nuosu would be concerned with Premi concepts of pollution might be the right question to ask if we focus primarily on ontology in a multicultural context. If we return to Espírito Santo and Blanes and take up their suggestion to first consider the 'effect' of intangible entities, we can drop the question for the time being. A soma being in trance is a powerful sensory experience, not just on the part of the soma, but, and maybe first and foremost, for the other persons present. Instead of pondering on the effects of beliefs, we can start by giving attention to the 'effects that produce beliefs, rationalizations, sensations, and their corollary-relations - thus, entities of all kinds' (Espírito Santo and Blanes 2014, 17). Old Trousers is clearly overawed by the very tangible and compelling intervention of an immaterial and powerful entity. At the scene, it was probably only the foreign anthropologist that was wondering whether the Nuosu held beliefs that were similar to that of the Premi in which water deities were acting on human behaviour in relation to disturbance and pollution of bodies of water.

\section{Managing the Intangible Entities of the Five Directions}

When not attending to the needs of ethnic outsiders or curious anthropologists, the soma was almost exclusively consulted by his co-villagers or by people living in the nearby villages, all situated on steep mountain slopes in the county of Muli in Sichuan, close to the Yunnan border. The villagers belong to the Tibeto-Burman speaking Premi people. As one of the more bizarre outcomes of the ethnic classification project by the Chinese state, the Premi living in Yunnan have acquired the separate minority 
nationality label of Pumizu, while their brothers and sisters, living on the other side of the provincial border in Sichuan, have been classified as Zangzu or Tibetans. According to Premi traditional cosmological understanding, lwéjabu reside in or near springs, lakes and rivers and are categorised according to the five directions in which they are found: North, South, East, West and Centre. They wield substantial power over human existence through their control over water, be it through regulating the weather - and as such agriculture — or through regulating the fluids of human and animal bodies and thereby being involved in a number of diseases and afflictions. They also wield power over lesser deities and evil spirits.

Lwéjabu are not only powerful but also vengeful and, unfortunately for the villagers, it is not easy to know which of their actions can cause the scorn of these deities. While it might be easy to avoid creating disturbances such as the cutting down of trees near so-called tirè - places where water comes out of the mountain or soil and well-known abodes of the lwéjabu - it can be more challenging to avoid hunting and killing 'wrong' animals. These animals are either animals that happen to be liked by a particular water deity, or, and this is worse - and might suggest that there are at least some similarities between Amazonian and Tibeto-Burman cosmology_-, sometimes deities appear to ordinary humans as animals.

Not only hunting, but also the traditional subsistence agriculture combined with pastoralism constantly forces people to risk creating disturbances for the deities. It is only after disaster has struck in the form of, for example, a devastating hail storm or a pervasive draught, that people assess some of their past actions as potentially having caused divine displeasure. This is where the soma can play his important part and convey to his fellow villagers why the lwéjabu might be infuriated. In his capacity as a medium, the soma shifts perspective: he is not only the voice of the deity, but he also can see differently than ordinary humans and, for example, 'see' the divine nature of some animals that have been hunted. In order to propitiate the deities, correct rituals will have to be performed. For that purpose, and for a whole number of other tasks in the business of keeping or restoring the balance in the intricate Premi cosmology, the villagers turn to ritual specialists or hangui. While the hangui might utilise the soma to find out what the deities are concerned with, the roles of the two are clearly distinct. The soma is a medium and does not have ritual competence. The 
hangui will select the appropriate ritual to conduct from among a whole array of an orally transmitted tradition that easily matches the complexity of this Premi cosmology. One of the more important rituals to the lwéjabu is called tserè; it is one of the seven basic rituals that every hangui should master. It is precisely their power over human existence in combination with the difficulties humans have in understanding their intentionality that give the lwéjabu a very strong degree of agency in Premi society. Humans can never feel that they have full control over their existence by just performing the right rituals at the exact time. Observed by their effects-in-the-world, deities and spirits 'constitute a potential for constant unpredictability and transgressiveness' (Espírito Santo and Blanes 2014, 6).

The lwéjabu make up one of the more powerful deities in the intangible dimension of this cosmology, but they are certainly not the only one. On top of the hierarchy are the heavenly gods Hladã Sonma and Yidã Sonma, powerful, but somehow aloof from day-to-day interference. Then there are mountain deities or rèda, deities of heaven and a whole array of lesser divinities, many of them associated with specific locales in uncultivated nature, such as areas in the forest, specific trees or bushes, rocks, bodies of water, etc. These inhabitants of the non-human or intangible dimension are neither hostile nor friendly in se towards human beings. From an ontological perspective, to a large extent these entities resemble humans in the way that they have emotions and react upon them. And they are considered to be highly susceptible towards human behaviour. Humans have therefore constantly to be on their guard and behave appropriately in relation to them. As such the deities are partly constituent in establishing moral behaviour. The close association of deities with the surrounding natural landscape puts humans in a delicate position because they depend on creating disturbances in this divine territory for their survival. Consequently, Premi attitudes towards their spatial surroundings seem, at first glance, to be guided by a respect for uncultivated nature, in the form of the avoidance of excessive cutting of trees, polluting lakes, digging holes or indiscriminate hunting.

Other inhabitants of the intangible dimension are less ambiguous in their relationship to humans. These are mainly the shep'a, a category of beings that can be translated as evil spirits. The shep'a are central in Premi understanding of disease. They are the ones that attack people or their domestic animals and cause disease or afflictions such 
as temporary or permanent loss of the soul. They can even cause death. Shep'a are most at home in the forest and prefer to dwell there, in trees, bushes, and caves or among stones. ${ }^{7}$ When villagers have to remain in or near the forest for a longer time, they are exposed to the shep'a. There are different ways of countering these malicious subjectivities: either by keeping them at bay through remedies such as protective charms (sungdï) or by uttering threatening spells, or by invoking the protection and assistance of some of the higher deities such as Hladã Sonma or Yidã Sonma. In places in the forest near water, the lwéjabu are most likely candidates as protecting deities. When tending their fields near the forest, for example, villagers will erect small makeshift altars to offer to the deities and implore their protection. The shep'a prefer to remain in the forest but, unfortunately for humans, they might find their way into the villages. One common way is by accompanying travellers crossing the forest, especially strangers from distant villages. In order to keep these spirits from entering the village, each major path leading into a Premi village has a spirit gate, two wooden poles connected on top by a board spanning over the path under which the visitor passes. On the board a magic spell in Tibetan script admonishes the shep'a to stop and return to the forest. According to several ritualists, one fortunate aspect for humans is that the shep'a have a rather simple perspective on their victims and are easily tricked by the highly effective spirit gates. In an interesting development, in some villages in Yunnan that have recently been confronted at their doorsteps with Chinese modernity in the form of motor-roads, elaborately adorned concrete spirit gates have been erected overarching the entrances into the village from the road. To some extent, the gates are a visual establishment of Premi ethnic identity in the multicultural modern Chinese state, nevertheless, at the same time, villagers insist that they prevent evil from the outside from entering the village. Again, supernatural beings such as the shep'a constitute unpredictable intentionalities with their own agenda of malevolence; consequently remedies with potential protective power should not be shunned.

The shep'a make up a rather diffuse category of malicious beings. One sort of shep'a are the wandering souls of deceased people. Similarly to the beliefs of many TibetoBurman groups, Premi in the villages of the Yunnan-Sichuan border region hold that humans are made up of a transient body as well as a separable and immortal soul. It is called drö or medrö (me means person, people) in Premi. After a person dies, the soul 
leaves the body and will have to find its way back to the ancestral lands of the clan to find peace. While death in itself is a key event in most societies, in Tibeto-Burman culture the entire process of the soul having to leave its corporal abode, make the journey to the ancestral lands, and, not to be neglected, remain there, is one of the pivotal epicentres of ritual activity. Both close kin and more distant clan members are involved in rituals and hangui will perform elaborate ceremonies to guide the soul of the deceased to join the souls of the other clan members.

At the level of the basic social unit of the Premi, the dzèn or 'house' community, the soul of the deceased will now join the ranks of the 'house-ancestors', that is those deceased family members who have lived in the house. ${ }^{8}$ As such, he or she will now be included in the ranks of those to be offered to every day by the inhabitants of the house. Every morning the bap' $u$, or the head of the household, will burn pine or juniper twigs into the hearth saying a prayer to honour the ancestors and ask for their protection. Before each meal somebody will place bits of food on the hsindrwè, the iron tripod used for cooking and on the drwama, the offering stone next to it. Through the food offerings, the sociality of the house is sanctified and remains interconnected with the invisible dimension of the natural world. There is actually little choice; these daily rituals have to continue as long as the house exists as a social unit in order to avoid ancestral souls in becoming evil shep'a. At other important ritual occasions such as the New Year ceremony, more elaborate offerings to the ancestors take place. There are different reasons why a house might not perform the offerings, but one of the most common grounds is that there are no living descendants around anymore. Wandering souls are restless and confused through their intermediate position of having left their place among their living kin and not having been settled yet among the ancestral kin. Therefore they keep close to the house they lived in and pester and plague first and foremost their close surviving kin. Nevertheless, when they are not able to find their surviving kin they become even more malicious and harass the other inhabitants of the village as well.

Except for displeased deities, souls turned evil spirits or shep'a, the surrounding natural environment contains a few other categories of metaphysical agents influencing Premi villagers' lives. Most Premi houses are, for example, equipped with a kadrã, an iron trident placed on top of the roof to keep the syè or wind demons from 
threatening its inhabitants. The majority of these beings are linked to the locale, either through elements of the geography or uncultivated nature, including the local villagers and their souls. Besides those shep'a who are believed to accompany travellers to the village, there is one more category of agents specifically associated with the dangers brought to the village by outsiders. While the travelling shep'a could relatively easily be tricked, for example by placing a spirit gate at the entrance of the village, brö demons are definitely much harder to deal with. For families considered to be haunted by brö demons the consequences are usually catastrophic. They become ostracised by the community and since there are supposed to exist no ritual remedies to rid them of the demons, not even the lwéjabu can be of any help. The affected families are not allowed to participate in common village rituals and they are visibly poorer than the other villagers, living in ramshackle houses, dressed in ragged clothing and family members often suffering from poor health. And, unfortunately for the following generations, the brö affliction will be inherited by the descendants, whether they move to somewhere else or remain in the house.

To make it even harder for those believed to be affected is that the existence of brö demons in Premi cosmology seems to be confirmed by their appearance in the cosmologies of other surrounding ethnic groups. This 'multi-cultural' aspect makes the brö into very powerful agents in local communities because the power of definition and identification is also into the hands of the wider world. While a Nuosu might have to exert some creativity in cultural conceptions to accept the advice of the lwéjabu, the brö demons are easily identified with comparable evils afflicting other ethnic groups. In discussing the brö, Premi would frequently mention the Chinese word $g u$. In Chinese folklore, gu is a poisonous creature with supernatural powers that comes into existence by putting different poisonous animals in a jar. It is thought to be used in witchcraft to obtain certain advantages, mostly by women, and in more recent times gu has often been associated with the Miao. ${ }^{9}$ The brö demons are said to have entered the village through contact with people belonging to the Na ethnic group. $\mathrm{Na}$ households are perceived by several of their neighbours as being particularly affected by gu or brö. In the countryside around the town of Yongning in Yunnan, which is the major area inhabited by the $\mathrm{Na}$, children of the other local ethnic groups 
can often be seen wearing a small magic pouch around their necks to protect them from the inflictions believed to be caused by their Na neighbours or class mates.

As with the gu, the brö are linked to the agency of women. Houses become afflicted by the brö demons through sexual contact with in-marrying women. Once they have established themselves in a house, the demons travel unhindered between all the afflicted houses, also those in other villages. They poison the food and bring about diseases to the inhabitants of the house and visitors such as disorders that cause the stomach to swell and make people vomit. But they also provide those afflicted with powers of casting spells onto others, hence the association with gu and witchcraft. In the same village where the soma lived, there were four families considered to have brö demons in their houses. The brö entered three generations ago when a girl from a neighbouring village married into the village. Her ancestral home had been affected a generation earlier by a girl coming from a Na household near Yongning. Few people in the village dared visiting their houses, let alone eat the food there. On my visit to the families alleged to be affected with the brö demons, none in my accompanying party of Premi and Nuosu was willing to enter into the houses. When Old Trousers, as the township policeman, had been forced to pay a visit to one of the families, he was threatened with a spell, something he did not brush off as superstition.

\section{Cosmology Challenged}

It would be wrong to assume that Premi cosmology has been able to survive as an ethnocentric understanding of the world merely because of the relative isolation of Premi communities on the steep mountain slopes of Southwest China. Chinese modernity or high Maoism were not the first challenges to Premi cosmology. For almost five hundred years Premi communities have lived in close contact with Tibetan Buddhism, and for even longer, but significantly less intimately, with Tibetan Bön religion. ${ }^{10}$ Ruled by an elite who legitimated its authority through the association with the Tibetan Buddhist Gelug School, Premi villagers in the area of Muli in Sichuan were forced to participate into monasticism by the rule that every second son in a household had to enter the monastery and become a monk. Although the policy never resulted in the conversion to Buddhism of the majority of the Premi in Muli, it has left its marks on ritual practice within the village communities. Tibetan, mainly 
Buddhist, ritual implements, as well as Buddhist and Bön texts have found their way out of the monasteries and become an important component of the major religious ceremonies. The texts are used for the magical power generated through the reciting. Almost none of the ritualists I talked to actually mastered a level of Tibetan language sufficient to understand significant parts of the content. Some terminology, such as the word soma designating the lwéjabu medium, has certainly entered the language through Tibetan Buddhism.

At the level of religious beliefs, the influence of Buddhism is less obvious. Premi cosmology shows a few similarities with Tibetan folk-beliefs such as mountain worship, but whether this is the result of a shared pre-Buddhist Tibeto-Burman religion or because of the intrusion of Tibetan religious concepts through Buddhism at a later stage is not always easy to assess. For example, the Premi word for deity, or divine entity, is hla, a word that it would seem logical to relate to the Tibetan word for deity, lha. But it is probably more likely that both terms have a common origin in preBuddhist times. Geoffrey Samuels links Tibetan lha to the concept of $l a$, the preBuddhist spirit-essence or life-principle (Samuels 1993, 187 and Wellens 2010, 134 135). The origin of some other aspects of religious worship is less ambiguous. Like several of their ethnic neighbours, Tibetans or some of the other Tibeto-Burman groups, most Premi houses have a small painting or semi-relief, called zambala, depicting the flaming eight-faceted jewel in Tibetan iconography, rinchen norbu or rinpoche. Because of its symbolic association with wealth, people in the house make regular offerings to the zambala in the hope that it will bring material prosperity to the house. The designation in the area of my fieldwork of two living persons, a man and a woman, as hla, or deities, is not similarly straightforward to explain. The concept of hla might be influenced by the Tibetan-Buddhist reincarnate lama's or tulku. The young girl in the village that was considered to be a living deity was recognised as such by a hangui ritualist, not by any Buddhist institution. She was expected to live in celibacy and follow strict dietary limitations, while spending her days studying Buddhist texts or go on occasional pilgrimages. Even though she was considered more focused on her own spiritual development, she was believed to possess both great knowledge as well as ritual efficacy. Her advice was sought, not only by her covillagers, but also by people living in more distant villages and even from other ethnic 
groups. Since she was the first hla in the village, the concept might have been a creative addition to traditional cosmology by the most knowledgeable and influential hangui ritualist in the village. While such a 'cultural innovation' might be partly inspired by poorly understood Buddhist notions, the evident way in which the living deity found her place within local religious beliefs and practices suggests references to existing indigenous concepts that are culturally logical.

In short, the case could be made that the Premi pantheon, myths of origin, the perception of immortal ancestral souls, classificatory systems, and so on, have basically survived as a separate indigenous system. Central Buddhist concepts such as reincarnation or karmic causality have not been able to make their entry into Premi ideas about the afterlife, while day-to-day moral life is maintained through regulating the relationship with the ancestral souls and the spirits and deities of nature.

At the discursive level, villagers and ritual specialists, view Buddhism and traditional hangui rituals as two combinatory systems relating to the same natural and supernatural world. In many Tibeto-Burman cultures in the periphery of Tibet, there is an archetypal competition between Buddhism and local indigenous ritual systems. In Premi villages, Buddhism is by many seen as a more advanced, but complementary system, concerned first and foremost with helping all humans to obtain a better life. It is habitually called Chwip'ö, which literally means "doing good deeds".

Paradoxically, people preoccupied with Buddhism are often viewed as distanced from the needs of the villagers because they are either living at the monastery, spending their time reading, going on pilgrimages or meditating. Nevertheless, Buddhist rituals are deemed useful in dealing with the supernatural, but they are seen as less effective in dealing with certain challenges of daily life, such as the evil actions of the shep'a. The prototypical difference between the two systems is exemplified in certain aspects of methodology: the hangui will make blood offers by killing domestic animals in rituals in order, for example, to scare away the shep'a; while a Buddhist trained lay priest will gently try to convince these evil spirits to leave a house by baiting them with some food outside. It has also been argued that Buddhism to some extent can exist simultaneously with other belief systems, and several scholars have even made the case that Buddhist monks can see advantages in such a co-existence by portraying 
local cults as an enduring 'other', characterised by poorly developed doctrines and primitive ritual methods such as the killing of animals. ${ }^{11}$

In spite of the hard-handed policies of forced participation in monasticism, Buddhism was not able to keep a foothold in the Premi villages of places like Muli, in Sichuan Province, or Yongning, in neighbouring Yunnan Province. In the 1960s the monasteries were closed down and the monks were sent back to their villages. After the Cultural Revolution, few of those monks were willing or, having broken basic Buddhist vows by marrying and setting up families, permitted to return. At the same time, villagers were trying to piece together again their religious life and were in dire need of ritual specialists; not only for starting to take up again regular rituals and ceremonies, but also to conduct a few important rituals to make-up for the disasters that took place during the years of the Cultural Revolution. One kind of rituals was aimed at dealing with a host of 'wandering souls' of people having died without the proper "soul-guiding" rites and therefore were lost in transformation. The villagers would call on both the few surviving hangui, as well as the monks that had been sent home to conduct services. On my visit to Premi villages in Muli around the change of the millennium, a few of these former monks were still active and reciting scriptures at cremation ceremonies or to ask the lwéjabu for rain. Besides them a new generation of freshly educated hangui ritualists is catering to the religious needs of the villagers. Very few villagers send their sons to the monastery and Buddhism's main foothold are the former and new urban elites.

In the face of the large, well-organised and politically powerful religion of Buddhism, the hangui tradition and Premi understandings of cosmology have shown themselves to be resilient, even among a small population. Rather than replacing these understandings and their remedies, Buddhism was conceived as a complimentary system and elements of Buddhism were incorporated into both local cosmology and ritual practice. While the lack of historical sources makes it difficult to study the details of hangui practice under Buddhism, we have significantly more data on the encounter of Premi traditional practices and beliefs with the ideologies of Maoism and Chinese modernity. 
Many of those studying the phenomenal resurgence of religious and ritual practices in China in the last thirty years have been concerned with understanding the context of the revival. Should the reconstruction of ritual complexes after the Cultural Revolution be viewed as a mere continuation of the pre Maoist past? Are people just taking up old habits now that repression of religion has ceased and nothing more? Authors such as Eric Mueggler and Jun Jing argue convincingly that it is precisely the experiences of the Maoist period that have triggered the revival and, to some extent, shaped it. ${ }^{12}$ Others have been focused on the role of the contemporary societal and political context in explaining the religious revival. ${ }^{13}$

The revival of hangui ritual practices is in part to be understood as Premi villagers restoring their religious habitus by taking up again their traditional ways of relating to the world they live in. But, as I have argued elsewhere, this world has been undergoing drastic changes, which in itself has contributed to the revival. With the collapse of basic but free social security provided by the commune, Premi villagers turned again to traditional remedies to help them cope with the adversities of life (Wellens 2010, 159-164). The process of restoring the hangui ritual complex was not straightforward though. Rituals had been orally transmitted among a relatively small cultural community and the pool of knowledgeable hangui was very little in the period right after the Cultural Revolution. This meant that the task of reconstruction was left to a few enterprising people who had to piece together a meaningful and coherent set of rituals from the bits and pieces that they or others remembered. These people needed to be respected as authorities on Premi cosmology by the community. The Tibetan Buddhist texts that were often recited in hangui rituals and that had not been burnt were not of much help in view of the fact that they were not used for their content.

But for a reconstructed ritual complex to be accepted by Premi villagers as relevant in coping with new and old challenges of life in the post Mao period, it has to be considered effective in dealing with the cosmos and its principles, forces and agents. The question is, how do villagers understand this cosmos to look like, and, further, how shared is their understanding? While the uncompromising and focused battle of the Mao years to eradicate local beliefs did obviously not achieve its goal, it was somewhat successful in that it made a number of people in the community doubt or 
reject some or the entirety of traditional beliefs. The subsequent era of economic reform bringing increasing contacts with Chinese modernity further eroded the homogeneity of cosmological understanding and related religious beliefs. In a survey I conducted in three Premi villages there was a clear correspondence between, on the one hand, the likelihood of consulting a hangui ritualist in stead of going to the hospital in case of disease in the family, and, on the other hand, the level of education and degree of contacts with the outside world. Not that people with a higher level of education would not consult a hangui ritualist, it was just not likely to be their first choice.

Of course, denying the existence of the deities and as such their subjectivity and agency is not a simple matter of personal choice, to be wrong might entail grave consequences. The ideological authority of the Maoist period seemed at first to present to the individual Premi villager a unique opportunity to rid him or her self safely from the yoke of the unpredictable and oppressing intentionalities of the supernatural. The available avenues were situated anywhere in between two extreme existentialist choices: either throw in one's lot entirely with communist ideology and become a liberated individual, rejecting traditional beliefs and practices as feudal superstition and embrace atheism, or, co-opt Mao into traditional cosmology as a new and powerful protector deity, joining or even replacing the lwéjabu and other deities. Almost three decades after his death, several houses in the villages I conducted fieldwork in still had a portrait of Mao hanging either beside the zambala or replacing it all together. The choices of individuals or families were contingent on different circumstances, such as class label or level of exposure to communist ideology. Some individuals or families had better reasons than others to question the universality of traditional cosmology. It was no coincidence that a local Red Guard leader belonged to one of the households considered to be affected with the brö demons. He was very active in destroying religious paraphernalia belonging to the hangui such as ritual texts or the zambala in people's houses. Since nobody dared to question his attack on traditional beliefs, the brö families had a short period of a few years of reprieve. But, as his fellow villagers explained, the revenge of the deities was merciless and the former Red Guards leader was bereft of his soul and turned mad after the ending of the Cultural Revolution. There is no one-to-one perspectival inversion: It's not 
because humans alter their view of the world of deities that the deities alter their view of the world of humans. The brö families became once again immersed in the same miserable existence. At the same time, the deities demonstrated that they did not shy away from taking on the Chinese state, if necessary.

\section{Chinese Modernity: Repurposing the Water Deities}

The handful of villages I conducted my fieldwork in, all had within its confines a green miniature grove consisting of a few trees, bamboo and other natural growth encircling a well or spring, the tirè. This was the place for worshipping the lwéjabu and therefore no plants could be disturbed within a circle of several metres surrounding it. The utter sacredness of the place was accentuated by the fact that no one would speak or make noise near the tirè, that is, except for the hangui ritualist performing rituals. Around the spring or well, a few oblong wooden tablets could be seen containing the images of animals living in the water, such as frogs, fishes and snakes. They are symbolic offers to the water deities. Premi traditional hangui religion does not have temples; rituals are mostly centred on the hearth in people's houses. The tirè are one of the view visible signs in the public sphere of a common relationship of the villagers with the supernatural dimension of Premi cosmology. In the evening, when it's quiet and there are less chances that disturbances will ruin communication with the deities, villagers can ask the hangui to conduct rituals here to cure them from 'watery' diseases, a category stretching from eye afflictions, skin diseases, to infertility or back aches. Especially since the implementation of birth control has become more stringent, the failure to produce male offspring is increasingly driving people to seek the help of the lwéjabu. Patrilineal descent is still an important element in Premi social organisation and therefore most couples will want at least one male child. In Muli, ethnic minorities were allowed three children, but families with four or five children were not that exceptional. This changed in 2003 when the fines for having more than three children increased from RMB 1,000 first to RMB 14,000, then shortly afterwards to RMB 18,000, an amount no family in the village was able to pay. While it was first and foremost women who went to ask for help in producing boys, it would not be unusual to see a couple making offerings next to a hangui ritualist reciting and using ritual implements. 
But it was not only the lwéjabu that were mobilised in assisting young couples in countering the negative effects of state policies. High up in the mountains in the northwest of the township, there was a large cave dedicated to the worship of a female deity, Hlamu. The cave was large enough to contain a small abode of a Buddhist hermit who once resided there. Traditionally, the cave was visited by women with 'women's diseases', including infertility which is mainly ascribed to women. In recent years, the most numerous visitors are couples making offerings to get male offspring. Not far away from the cave, a whole river emerged from a crack in the mountain. This place was visited by couples wishing female offspring. In contrast to the cave, there were no traces of offerings to be seen there.

While the village spring with its sacred grove constituted the place of day-to-day contact between villagers and the lwéjabu, more important ceremonies were held near larger bodies of water, such as mountain lakes. These were both annually recurring ceremonies relating to the agricultural calendar, as well as more ad hoc events. The major purpose of these longer and relatively elaborate rituals was to settle the relationship between humans and the lwéjabu on a more general level so that these deities will do their job of regulating water. Around the change of the millennium, a large communal ceremony involving the whole village (with the exception of the brö afflicted houses) was held to implore the lwéjabu for rain. For three days, the villagers stayed beside a lake a couple of hours walking from the village while several hangui would perform extended rituals, a number of those involving the offerings of animals. In order to enhance ritual efficacy, the female hla was asked to participate and spent hours reciting Buddhist scriptures. Some of the religious activities are more preemptive than responsive: Once a year, the hangui and the soma make a trip to a mountain lake where they spend the day conducting rituals and, through the medium, they are able to become acquainted with the perspective of the deities. The main purpose of the visit is to obtain specific information regarding certain trees or animals to be left unharmed by humans. This contributes to a better relationship between deities and humans, but the fact that they have to do this once a year also testifies to the unpredictability of extra-human intentionalities and motivations (Viveiros de Castro 1998, 472). This again imbues the supernatural dimension with strong agency and puts humans in a subservient position. 
There are only very few ethnographic descriptions of hangui practices of the precommunist era. According to a study by Yang Xuezheng, these practices consisted of intrinsic sets of rituals dealing with a well-developed categorisation of disease causing shep'a, dividing them according to 'watery', 'dry', 'windy' etc. Hangui ritualists had to be able to find out which kind of evil spirit was responsible for the affliction and then perform the appropriate ritual. Yang describes very elaborate rituals, often involving killing of domestic animals and the invocation of higher deities for assistance (Yang 1991). When the world changed and the health situation improved radically in the region, including the eradication of endemic leprosy and bubonic plague, the threat of the shep'a also seemed to lessen and the main focus of ritual needs shifted to other areas. The collective system of the period of high Maoism removed some of people's individual responsibility in insuring their own livelihood, which further diminished the need for divine assistance in coping with nature. But even the Cultural Revolution did not manage to extinguish Premi cosmology and with the Reform Period of the late 1970s hangui practices were revived. In the process of reclaiming their place in the cosmological scheme of things the deities first had a few scores to settle such as snatching the soul of the Red Guards leader who had defied them a few years earlier. The villagers were now faced with new problems related to a gap left by the retreating of an invasive but providing state. The subsequent disappearance of the communes not only caused the break down of the basic but free medical health system but also took away the principle of risk sharing in agricultural production. With the newly established household responsibility system, a Premi house could now be thrown into long term misery by a bad harvest or disease of people or domestic animals. People almost literally felt they had to face their demons again by themselves and turned to the assistance of the deities to combat the afflictions by the shep'a and control the forces of water and wind.

But while the state retracts from some areas of society, especially at the end of the 1990s and into the new millennium it re-enters into other domains. Besides meddling in some of the more fundamental aspects of life through birth control policies, the state is now seen as interfering increasingly strictly in areas relating to people's livelihood and their relation to their natural surroundings. The biggest one-time blow in the post Mao years was the 1998 official ban on cutting down natural forest in the 
Southwest following the disastrous flooding in Central China the preceding years. This effectively reduced the revenues in the county of Muli with $90 \%$ and the large contingent of Premi working in logging or logging related business lost their jobs and had to return home. From the start of the new millennium policies on land use became increasingly strict. People were not allowed anymore to freely cut trees in the surrounding forest to build, repair or enlarge their houses. Villages were given annual quota and waiting lists quickly became very long. Levels of frustration were high, and several of those who did not wait for a permit and cut trees without it were caught and given high fines. But also traditional subsistence agriculture came under growing attacks through campaigns aiming at countering soil erosion. The Grain for Green (Tui Geng Huan Lin) Project was launched to return cultivated land on slopes of $25^{\circ}$ or more to forestland in the upper Yangtze River Basin (Ye, Chen, and Fan 2003). While people initially were positive because participation was voluntary and compensation seemed attractive, the mood changed when pressure increased and families who were not interested in participating felt forced to change their way of life. Through adding limitations and complications in the daily relationship of the villagers with the forces of nature, the state became increasingly conceptualised in line with other challenges such as deities with inscrutable intentionalities or the evil spirits residing in the forest. This is different from the Maoist period when the state radically challenged local cosmological understanding of the relationship with the forces of nature and tried to impose its alternative ideology. As one villager expressed it: 'Mao told us there were no shep'a! And if there were shep'a, he surely would protect us!' Even though the Maoist state did not manage in the end to replace Premi cosmology, for some time it seriously challenged the agency of the lwéjabu and other deities. But not anymore, in the post Mao state, villagers ask the lwéjabu for assistance in countering state policies, and it will not take long before hangui rituals for exorcising shep'a will be recycled to keep out county forest inspectors or family planning controllers.

\section{Concluding Remarks}

This article has explored how it is conceivable that local ritual traditions can reaffirm themselves as meaningful and relevant for small ethnic minority communities surviving mainly on subsistence farming at the periphery of modernising Chinese 
society. One important prerequisite is that the totalising cosmology that these traditions address manages to continue transcending ethnocentrism and in this way maintain some claim to universal validity. As such, villagers - and especially ritual specialists - cannot, as in traditional western social science, subscribe to the view that their own cultural system is but one way to respond to a common nature. By focusing on the 'effects' of divine entities, we can infer how villagers are mostly concerned with which entities do a good job in addressing their concerns rather than whether the entire system is coherent. Traditionally, divine agency built on a strong authority over the forces of nature, which was maintained by an inscrutable intentionality. Since villagers were uncertain about how their necessary disturbances of forests, bodies of water or other elements of their natural surroundings might be offensive to divine and supernatural powers, they were at the mercy of these powers for re-establishing a balance with nature. At the end of the Mao period, the lwéjabu and other deities managed to demonstrate their agency once again by displaying an extreme vengefulness towards those who had questioned their authority or even their existence. In the Reform Period, the State did not directly challenge Premi cosmology head-on as it had done during the Cultural Revolution. Nevertheless, the legitimacy and authority of the deities becomes now challenged by the encounter with the forces of encroaching modernity. In at least one aspect, they live up to the mark, that is, in establishing agency across ethnic boundaries. Increasingly, this agency is sought by the community of subsistence famers in dealing with the interferences of the state. It is yet unclear whether new developments such as the concrete spirit gates erected between the village and the motor-roads express a conceptual shift by which outside threats are perceived as originating in China's ever-expanding urban centres rather than in the shrinking forests.

\section{References}

Belleza, J. V. 2005. Spirit-Mediums, Sacred Mountain and Related Bon Textual Traditions in Upper Tibet: Calling Down the Gods. Edited by H. Blezer, A. McKay and C. Ramble. Vol. 8, Brill's Tibetan Studies Library. Leiden, Boston: Brill. 
Chau, A. Y. 2006. Miraculous Response: Doing Popular Religion in Contemporary China. Stanford, Calif.: Stanford University Press.

da Col, G. "The View from Somewhen: Events, Bodies and the Perspective of Fortune around Khawa Karpo, a Tibetan Sacred Mountain in Yunnan Province." Inner Asia 9, (2007): 215-235.

Dargyay, E. K. 1988. Buddhism in Adaptation: Ancestor Gods and their Tantric Counterparts in the Religious Life of Zanskar. History of Religions 28 (2): $123-134$.

Descola, P. 2013. Beyond Nature and Culture. Translated by J. Lloyd. Chicago: University of Chicago Press. Original edition, Par-delà nature et culture.

Diamond, N. 1988. The Miao and Poison: Interactions on China's Southwest Frontier. Ethnology 27 (1): 1-25.

Espírito Santo, D., and R. Blanes. 2014. "Introduction: On the Agency of Intangibles." In The Social Life of Spirits, edited by D. Espírito Santo and R. Blanes, 1-32. Chicago and London: The University of Chicago Press.

Jing, J. 1996. The Temple of Memories: History, Power, and Morality in a Chinese Village. Stanford: Stanford University Press.

Mueggler, E. 2001. The Ae of Wild Ghosts: Memory, Violence, and Place in Southwest China. Berkeley: University of California Press.

Samuels, G. 1993. Civilized Shamans: Buddhism in Tibetan Societies. Washington, D. C.: Smithsonian Institution Press.

Siu, H. F. 1989. Recycling Rituals: Politics and Popular Culture in Contemporary Rural China. In Unofficial China: Popular Culture and Thought in the 
People's Republic, edited by P. Link, R. Madsen and P. G. Pickowicz. Boulder, San Francisco, \& London: Westview Press.

Viveiros de Castro, E. 1998. Cosmological Deixis and Amerindian Perspectivism. The Journal of the Royal Anthropological Institute 4 (3):469-488.

— 2004. EXCHANGING PERSPECTIVES: The Transformation of Objects into Subjects in Amerindian Ontologies. Common Knowledge 10 (3):463-484.

Wellens, K. 2010. Religious Revival in the Tibetan Borderlands: The Premi of Southwest China, Studies on Ethnic Groups in China. Seattle: University of Washington Press.

2012. "Migrating Brothers and Party-State Discourses on Ethnic Origin in Southwest China." In Origins and Migrations in the Extended Eastern Himalayas, edited by T. Huber and S. Blackburn, 299-319. Leiden; Boston: Brill.

Yang X. 1991. Ninglang Xian Pumizu Zongjiao Diaocha (Investigation into the Religion of the Pumi Nationality of Ninglang County). In Yunnan Shaoshu Minzu Shehui Lishi Diaocha Ziliao Huibian. Kunming: Yunnan Renmin Chubanshe.

Ye Y., Chen G., and Fan H.. 2003. Impacts of the "Grain for Green" Project on Rural Communities in the Upper Min River Basin, Sichuan, China. Mountain Research and Development 23 (4):345-352.

\section{Notes}

${ }^{1}$ I would like to thank Giovanni da Col and two anonymous reviewers for their valuable comments. 
${ }^{2}$ Premi words are written in such a way that they approximate the English pronunciation of the letters with the following exceptions: $e$ corresponds to the French $e ́, \grave{e}$ to the first $e$ in English enter, $i$ as in the English $i n, \ddot{u}$ and $\ddot{o}$ as in German, ' after a consonant indicates a strong aspiration, and on top of a vowel marks a nasalisation of the syllable.

${ }^{3}$ This is also reflected in their mythology, see Wellens (2012).

${ }^{4}$ Living on the periphery of the Tibetan area, it is unclear whether the medium among the numerically small ethnic group of the Premi is a long standing indigenous tradition or whether the institution constitutes an adoption from Tibetan practice. The appellation soma might at least suggest a relation to the Tibetan srung-ma (see, for example, Belleza 2005 and Wellens 2010, 154-156).

${ }^{5}$ In order to protect the names of my informants I use pseudonyms. 'Old Trousers' is the translation of an actual Nuosu name, given to a person to trick the evil spirits in assuming that the person is not worthy of harassing.

${ }^{6}$ See, for example, Descola $(2013,11)$.

${ }^{7}$ They are reminiscent of the $l u$ or sadak of the Tibetans in neighbouring Dechen, also in the aspect that it is hard to avoid disturbing them when practicing agriculture or just entering the forest. See, for example, da Col (2007, 219).

${ }^{8}$ Wellens discusses in more detail the concept of 'houses' as the basic form of Premi social organisation. 'Houses' have names, and these are part of people's names and used instead of family names. While each village included a 'leading' house (Bésé), traditional Premi society seems to have had very little social stratification and the 'house society' was mainly egalitarian. I have suggested that to the extent stratification existed, it was the result of the super positioning of hierarchy following the incorporation of the Premi area into Tibetan Buddhist Gelug monasticism. See Wellens (2010, 94-131).

${ }^{9}$ Norma Diamond argues that the association of poison with the Miao and other ethnic minorities in the Southwest is not older than a few hundred years. The character $g u$ (盅) is at least 3,000 years old and can be found in Chinese texts over a 
2,000-year period. The concept of poison in a jar to obtain advantages is therefore more likely to have originated in Han Chinese folk-religion than coming from the Miao (Diamond 1988).

${ }^{10}$ With the rise of the Gelug School of Tibetan Buddhism since the beginning of the $17^{\text {th }}$ century, Bön has only had a marginal presence in the larger Muli-Yongning border area with only a handful of small temples. The impact on hangui ritual is unclear but a certain number of texts recited by the hangui ritualists are of Bön origin such as invocations of the Bön deity Welchen Meri and the Bön sages Drenpa Namkha and Tsewang Rigzin (Wellens 2010, 151).

${ }^{11}$ For co-existence with Tibetan Mahayana, see, for example Dargyay (1988, 133).

${ }^{12}$ See Mueggler (2001) and Jing (1996).

${ }^{13}$ See, for example, Chau (2006) and Siu (1989). 